\title{
KOMUNIKASIRINGKAS
}

\section{UJI PROGENI INDUK BETINA NILA GIFT (Oreochromis sp.) HASIL FEMINISASI UNTUK MENDAPATKAN BETINA FUNGSIONAL XY}

\author{
Titin Kurniasih, Otong Zaenal Arifin, dan Estu Nugroho
}

\begin{abstract}
ABSTRAK
Uji progeni terhadap 200 ekor induk nila betina hasil feminisasi (pengalihan kelamin dari jantan menjadi betina) untuk mendapatkan induk nila betina fungsional $X Y$ dalam rangka pembentukan induk nila jantan homogamet $Y Y$ telah dilakukan. Penelitian ini bertujuan untuk menentukan induk nila betina fungsional $X Y$ di antara 200 induk betina tersebut. Masing-masing induk betina dipijahkan dengan jantan normal $(X Y)$ secara berpasangan dalam hapa yang terpisah. Keturunan yang dihasilkan dipelihara di waring secara terpisah dan diidentifikasi kelaminnya secara manual setelah berumur 4 bulan. Parameter utama yang diamati adalah proporsi kelamin betina-jantan dan derajat sintasan dari tiap kelompok anak yang dihasilkan. Data yang diperoleh menunjukkan ada 3 ekor induk ikan nila betina yang menghasilkan keturunan jantan sebanyak lebih dari $75 \%$ (betina fungsional $X Y$ ) dan 1 ekor yang menghasilkan keturunan jantan lebih dari $70 \%$. Selama 3 bulan pemeliharaan, tingkat sintasan benih dari betina fungsional antara 70,2\%$82,1 \%$ berada pada kisaran rata-rata tingkat sintasan normal secara keseluruhan, yaitu sebesar $72,8 \%$.
\end{abstract}

ABSTRACT: Progeny testing of female nile tilapia GIFT (Oreochromis sp.) broodstocks derived from feminization process using estradiol to obtain the $X Y$ genotipically functional female fish. By: Titin Kurniasih, Otong Zaenal Arifin, and Estu Nugroho

A progeny testing was conducted to 200 female nile tilapia GIFT (Oreochromis sp.) broodstocks that had been treated by feminization process at larval stage using estradiol to obtain the $X Y$ genotipically sex-reversed female nile tilapia broodstocks. This research was part of the effort to form YY supermale nile tilapia broodstocks. The objective of this research was to determine the female broodstocks that functionally and phenotipically female but genotipically male (XY) among the 200 female broodstocks tested. Each of the female broodstock was mated with one normal male $(X Y)$ broodstock in pairs in separate hapas. The resulted off springs were also reared in separated net cages and sexing was carried out manually after reaching of 4 month age. The main parameters observed in this research were the male-female proportions and survival rate in each of the female broodstocks'brood. Result of this research showed there were 3 individuals of female broodstocks that had produced $75 \%$ of male progenies (XY-genotipically functional female) and 1 individual of female broodstocks that had produced $70 \%$ of male progenies. Survival rates of the four functional females during the three months rearing period were ranged between $70.2 \%$ to $82.1 \%$.

KEYWORDS: progeny testing, female tilapia, manually sexing, sex proportion, functional female

\section{PENDAHULUAN}

Telah lama diketahui, bahwa upaya peningkatan produksi budi daya ikan nila (Oreochromis sp.) banyak terhambat oleh beberapa sifat khas ikan nila itu sendiri, yaitu kematangan seksual yang terlalu dini sehingga reproduksinya menjadi tidak terkontrol. Hal ini mengakibatkan pertumbuhan tubuh ikan nila menjadi lambat karena energi yang diperoleh dari pakan lebih banyak digunakan untuk kepentingan pematangan kelamin dan bereproduksi daripada untuk pertumbuhan tubuhnya (Wohlfarth \& Hulata, 1981). Beberapa metode untuk meningkatkan produksi nila telah banyak disarankan dan dicobakan antara lain dengan penggunaan spesies predator yang sesuai (Guerrero, 1982), produksi larva steril melalui

Peneliti pada Balai Riset Perikanan Budidaya Air Tawar, Bogor 
triploidisasi, dan dengan menyilangkan nila hibrid untuk memproduksi keturunan tunggal kelamin (Pruginin et al., 1975; Hanson et al., 1983; Majumdar \& McAndrew, 1983). Produksi massal larva tunggal kelamin jantan pada ikan nila merupakan salah satu alternatif pemecahan masalah di atas, karena dapat mencegah terjadinya reproduksi yang tak diinginkan. Pada ikan nila, individu jantan memiliki kecepatan tumbuh jauh di atas individu betina (Jangkaru et al., 1988). Namun, khususnya untuk Indonesia, cara memproduksi larva monoseks jantan secara massal yang dapat dilakukan secara rutin dan konsisten belum ditemukan.

Upaya memproduksi larva monoseks jantan juga dapat dilakukan melalui perlakuan hormon steroid. Keberhasilan memperoleh keturunan monoseks jantan pada spesies Oreochromis menggunakan hormon testosteron telah banyak dilaporkan, sebagai contoh, Clemens \& Inslee (1968) pada Oreochromis mossambicus, Tayamen \& Shelton (1978) pada Oreochromis niloticus, dan Shelton et al. (1978) pada Oreochromis aureus. Metode seks reversal menggunakan hormon pada stadium larva ini memiliki banyak kelemahan antara lain diperlukan tenaga ahli dalam pelaksanaan teknisnya, tingkat keberhasilan yang tidak konsisten, dan juga adanya kekhawatiran mengaplikasikan hormon secara langsung pada ikan yang akan dikonsumsi manusia.

Pengembangan induk nila yang secara konsisten mampu menghasilkan keturunan tunggal kelamin jantan (tanpa penggunaan hormon secara langsung pada ikan nila yang akan dikonsumsi manusia) merupakan langkah maju dalam dunia budi daya ikan. Untuk spesies Oreochromis sp. yang individu betinanya bergenotif $X X$ dan individu jantannya bergenotif $X Y$, maka perlu merekayasa agar dihasilkan individu nila jantan bergenotip $Y Y$, yang lebih dikenal dengan istilah $Y Y$ Supermale (jantan super $Y Y$ ), yang apabila dikawinkan dengan betina normal $X X$, akan menghasilkan keturunan 100\% jantan (Scott et al., 1989). Yamamoto (1961) berhasil menghasilkan YY Supermale pada Oreochromis latipes dengan cara mengawinkan betina fungsional bergenotip jantan (XY) dengan jantan normal XY. Yamamoto (1963) melaporkan bahwa jantan super YY dapat dialihkan kelaminnya menjadi betina fungsional bergenotip $Y Y$ pada fase larva dengan terapi hormon estrogen.

Menurut Gordon et al. (1995), tahap awal untuk mendapatkan nila jantan super $Y Y$ adalah dengan feminisasi, yaitu pembalikan kelamin nila jantan normal $X Y$ menjadi betina fungsional $X Y$ pada fase larva menggunakan hormon. Tahap kedua adalah mengawinkan betina fungsional $X Y$ tersebut dengan jantan normal $X Y$ sehingga akan menghasilkan keturunan $25 \%$ betina $X X, 50 \%$ jantan $X Y$, dan $25 \%$ jantan $Y Y$.
Penelitian ini bertujuan untuk mendapatkan indukinduk betina fungsional $X Y$ melalui uji progeni, yang teridentifikasi dari proporsi kelamin anak yang dihasilkannya (lebih dari 75\% berkelamin jantan).

\section{BAHAN DAN METODE}

Percobaan ini merupakan tahap kedua dari enam tahap pembentukan induk nila jantan super YY secara massal, yang secara garis besar adalah sebagai berikut:

\section{Tahap I. Feminisasi dengan hormon estradiol (tahun 2000)}

Ikan yang digunakan dalam tahap ini adalah larva ikan nila GIFT berumur 6 hari dengan ukuran panjang $15 \mathrm{~mm}$ dan bobot $0,05 \mathrm{~g}$.

Hormon yang dipakai dalam percobaan ini adalah hormon estradiol-17b (1,3,(10)-Estratriene-3, 17b-diol). Hormon ini berwarna putih dan berbentuk serbuk halus diproduksi oleh Sigma Chemical Co, USA. Hormon tersebut lebih dikenal dengan nama estradiol 17-b.

Pakan yang diberikan pada larva ikan berupa pelet komersil halus dengan kadar protein $40 \%$ yang dicampur hormon estradiol 17-b dengan dosis $100 \mathrm{mg}$ estradiol 17-b per kilogram pakan.

Penyiapan hormon dilakukan dengan cara menimbang hormon sebanyak $100 \mathrm{mg}$, kemudian hormon dilarutkan dalam $500 \mathrm{~mL}$ ethylalkohol $70 \%$. Larutan hormon tersebut kemudian dicampurkan dalam $1 \mathrm{~kg}$ pakan, diangin-anginkan sampai kering, disimpan dalam wadah yang tertutup rapat dan disimpan di tempat yang tidak terkena sinar matahari.

Pakan berhormon diberikan pada ikan uji selama 21 hari sebanyak 5\% bobot biomassa per hari. Frekuensi pemberian pakan dilakukan dua kali sehari. Setelah treatment pemberian pakan berhormon selesai dilakukan (21 hari), larva dipindahkan ke hapa untuk pembesaran selama 2 bulan berikutnya.

Setelah masa 2 bulan pemeliharaan di hapa, benih nila tersebut kemudian dipilah antara kelamin jantan dan betina secara manual dengan melihat genitalnya. Semua ikan yang berkelamin jantan dibuang, sedangkan yang betina diamankan dan dipelihara hingga matang gonad dan siap memijah.

\section{Tahap II. Uji progeni terhadap ikan nila betina hasil pengalihan kelamin pada Tahap I (2001)}

Dari penelitian Tahap I telah dihasilkan 200 ekor induk nila betina yang siap memijah. Ke-200 ekor induk nila betina inilah yang akan menjalani uji progeni.

Uji progeni dilakukan terhadap 200 induk betina tersebut dengan cara memijahkan 200 ekor jantan normal secara berpasangan dalam hapa yang 
terpisah. Pemijahan dilakukan 2 tahap, dan setiap tahap 100 ekor induk betina dan 100 ekor induk jantan dipijahkan secara berpasangan dalam 100 buah hapa berukuran $2 \times 1 \times 1 \mathrm{~m}^{3}$. Sebelum pemijahan, dilakukan pematangan gonad selama 1 bulan di kolam pematangan, dilakukan secara terpisah antara induk jantan dan betina. Induk yang matang gonad kemudian diberi tag (tanda) dan dipijahkan dalam hapa, dengan jumlah induk untuk setiap hapa adalah 1 ekor jantan dan 1 ekor betina.

Lanva ikan hasil pemijahan terlebih dahulu dihitung jumlahnya, dibiarkan di dalam hapa untuk dilakukan pemeliharaan lebih lanjut selama 1 bulan. Benih ikan kemudian dipindahkan ke dalam waring untuk pemeliharaan selama 2 bulan sampai dapat dibedakan jenis kelaminnya secara manual.

Setiap kelompok keturunan yang berasal dari induk jantan dan betina sama dipelihara dalam satu waring dan ditandai sehingga mudah menentukan keturunan setiap induk betina.

Identifikasi kelamin secara manual dilakukan dengan cara membedakan bentuk genital ikan uji, dilakukan terhadap seluruh ikan uji dari masing-masing kelompok keturunan.

Setelah masing-masing kelompok anak diidentifikasi kelaminnya, dan diketahui perbandingan kelamin anak jantan dan betina tiap-tiap induk, maka hanya induk dan keturunannya yang memenuhi syarat (75\% atau lebih jantan) yang dipelihara lebih lanjut, sedangkan yang lain dibuang. Induk-induk ini diduga merupakan betina heterogamet $\mathrm{XY}$, sedangkan keturunannya yang berkelamin jantan, diduga sebagian daripadanya adalah jantan homogamet $Y Y$. Oleh karena itu, semua anakan yang berkelamin jantan disimpan untuk dipelihara lebih lanjut, sedangkan yang betina dibuang. Keturunan jantan dari induk-induk betina fungsional $X Y$ ini akan menjalani uji progeni tahap III.

\section{HASIL DAN BAHASAN}

Dari 200 ekor induk betina hasil pengalihan kelamin yang dipijahkan, sebanyak 41 ekor induk memijah. Benih hasil pemijahan dipelihara selama 3 bulan sampai mencapai ukuran rata-rata $30-50 \mathrm{~g}$. Setiap kelompok benih yang sekandung (memiliki induk betina yang sama) dipelihara bersama dalam satu waring dan terpisah dari kelompok anakan lainnya.

Setelah dilakukan pengujian secara manual terhadap jenis kelamin anakan, 37 ekor induk betina menghasilkan keturunan dengan proporsi kelamin jantan dan betina mendekati sebanding $(50 \%: 50 \%)$ dan 4 ekor induk betina menghasilkan keturunan dengan persentasi jumlah anak berkelamin jantan masing-masing $73 \%, 76 \%, 84 \%$, dan $86 \%$ (Tabel 1).
Berdasarkan data yang diperoleh, dari 41 ekor induk yang memijah diduga 4 ekor induk betina adalah berkromosom $X Y$ (sekitar $9,7 \%$ ), yang dapat dilihat dari data proporsi anakan jantan yang mencapai sekitar dan lebih dari $75 \%$. Sementara pada induk betina lainnya, proporsi anakan jantan betina mendekati seimbang atau di bawah $70 \%$. Gordon et al., (1995) berpendapat bahwa persilangan antara jantan normal $(X Y)$ dengan betina fungsional heterogamet $(X Y)$ akan menghasilkan sekitar $25 \%$ ikan jantan homogamet $(Y Y), 50 \%$ jantan normal $(X Y)$ dan $25 \%$ betina normal $(X X)$, di mana komposisi ini bisa berubah setelah ikan dewasa tergantung daya tahan hidupnya. Pada ikan Oreochromis aureus, Jensen \& Shelton (1979) melaporkan bahwa dari 100 ekor betina hasil pengalihan kelamin yang telah dirangsang dengan estrogen kemudian dikawinkan dengan jantan normal, sebanyak 41 ekor memijah. Dari pemijahan tersebut 5 ekor menghasilkan keturunan $100 \%$ jantan, 1 ekor menghasilkan keturunan $95 \%$ jantan, 1 ekor menghasilkan $100 \%$ keturunan betina, dan sisanya menghasilkan keturunan dengan ratio kelamin jantan betina 1:1.

Rata-rata sintasan ikan nila selama masa pemeliharaan 3 bulan, mendekati kisaran normal, yaitu sebesar $72,8 \%$ dengan sintasan terendah $53,9 \%$ dan tertinggi sebesar $82,1 \%$ (Tabel 1). Pada ikan Salmo gardeineri, Parsons \& Thorgaard (1985) mengungkapkan bahwa daya tahan hidup ikan $Y Y$ adalah sempurna, hal ini dibuktikan dengan ratio jantan betina populasi anak hasil persilangan antara individu jantan tanpa perlakuan dengan betina fenotip adalah 3:1, demikian juga pada ikan medaka (Yamamoto, 1964), coho salmon (Hunter et al., 1982).

Secara umum, dengan adanya indikasi keberadaan induk betina heterogamet $X Y$, yang ditandai dengan proporsi anakan jantan lebih tinggi dibanding proporsi anakan betina, menandakan bahwa proses pengalihan kelamin menggunakan $17 \mathrm{~b}$ estradiol dengan dosis $100 \mathrm{mg} / \mathrm{kg}$ pakan pada tahun sebelumnya telah berhasil. Yamamoto (1969) berpendapat bahwa dosis yang tepat sangat berpengaruh pada tingkat keberhasilan pembalikan kelamin, demikian juga dengan jenis steroid dalam takaran tertentu semakin tinggi dosis yang diberikan, proporsi kelamin ikan yang diharapkan akan semakin meningkat, namun bila dosis yang diberikan terlalu tinggi maka proporsi ikan mandul yang akan tinggi (Hishida \& Kawamoto, 1970). Sementara Eckstein \& Spira (1965) berpendapat bahwa pada dosis estrogen yang ekstrem, efek penghambatan gonadogenesis semakin kuat, sehingga menghasilkan kasus kemandulan total dan mortalitas yang tinggi.

Secara umum, besar kecilnya hasil yang dicapai bukan merupakan indikasi akhir dari keberhasilan 
Kurniasih, T., Zaenal, O., dan Nugroho, E.

Tabel 1. Proporsi kelamin dan sintasan benih hasil pemijahan ke-1 dan ke-2 induk nila betina hasil feminisasi

Table 1. Male-female proportion and survival rate of off spring derived from first and second matings of feminized female broodstocks

\begin{tabular}{|c|c|c|c|c|c|c|c|}
\hline \multirow[t]{2}{*}{$\begin{array}{l}\text { No. tag } \\
\text { Tag number }\end{array}$} & \multicolumn{2}{|c|}{$\begin{array}{l}\text { S keturunan (ekor) } \\
\text { S off spring } \\
\text { (individu) }\end{array}$} & \multicolumn{2}{|c|}{$\begin{array}{l}\text { Proporsi kelamin } \\
\text { jantan } \\
\text { Proportion of male } \\
\text { off spring }\end{array}$} & \multicolumn{2}{|c|}{$\begin{array}{c}\text { Proporsi Kelamin } \\
\text { Betina } \\
\text { Proportion of female } \\
\text { off spring }\end{array}$} & \multirow[t]{2}{*}{$\begin{array}{l}\text { Sintasan }(\%) \\
\text { Survival rate }(\%)\end{array}$} \\
\hline & $\begin{array}{l}\text { Awal } \\
\text { Initial }\end{array}$ & $\begin{array}{l}\text { Akhir } \\
\text { End }\end{array}$ & $\begin{array}{l}\text { Jumlah } \\
\text { Number of }\end{array}$ & $\begin{array}{l}\% \\
\%\end{array}$ & $\begin{array}{c}\text { Jumlah (ekor) } \\
\text { Number of }\end{array}$ & $\begin{array}{l}\% \\
\%\end{array}$ & \\
\hline AB 098 & 360 & 194 & 78 & 40.2 & 116 & 59.8 & 53.9 \\
\hline $\mathrm{AB} 016$ & 463 & 373 & 156 & 41.8 & 217 & 58.2 & 80.6 \\
\hline AB052 & 432 & 332 & 150 & 45.2 & 182 & 54.8 & 76.9 \\
\hline $\mathrm{AB} 043$ & 451 & 346 & 160 & 46.2 & 186 & 53.8 & 76.7 \\
\hline AB039 & 467 & 351 & 168 & 47.9 & 183 & 52.1 & 75.2 \\
\hline AB096 & 434 & 348 & 168 & 48.3 & 180 & 51.7 & 80.2 \\
\hline $\mathrm{AB} 057$ & 517 & 419 & 205 & 49.0 & 214 & 51.0 & 81.0 \\
\hline AB059 & 509 & 394 & 200 & 50.8 & 194 & 49.2 & 77.4 \\
\hline AB075 & 512 & 405 & 210 & 51.9 & 195 & 48.1 & 79.1 \\
\hline $\mathrm{ABO37}$ & 487 & 317 & 167 & 52.7 & 150 & 47.3 & 65.1 \\
\hline AB054 & 495 & 387 & 204 & 52.7 & 183 & 47.2 & 78.2 \\
\hline AB069 & 498 & 381 & 202 & 53.0 & 179 & 47.0 & 76.5 \\
\hline AB070 & 353 & 284 & 153 & 53.9 & 131 & 46.1 & 80.5 \\
\hline AB088 & 423 & 308 & 172 & 55.8 & 136 & 44.2 & 72.8 \\
\hline AB050 & 494 & 392 & 219 & 55.9 & 173 & 44.1 & 79.4 \\
\hline AB091 & 478 & 367 & 205 & 55.9 & 162 & 44.1 & 76.8 \\
\hline AB063 & 396 & 296 & 172 & 58.1 & 124 & 41.9 & 74.7 \\
\hline AB097 & 403 & 274 & 160 & 58.4 & 114 & 41.6 & 68.0 \\
\hline AB055 & 410 & 294 & 173 & 58.9 & 121 & 41.1 & 71.7 \\
\hline AB068 & 312 & 216 & 130 & 60.2 & 86 & 39.8 & 69.3 \\
\hline AB062 & 488 & 378 & 238 & 63.0 & 140 & 37.0 & 77.5 \\
\hline ABO34 & 402 & 236 & 159 & 67.4 & 77 & 32.6 & 58.7 \\
\hline AB060 & 322 & 218 & 150 & 68.9 & 68 & 31.1 & 67.7 \\
\hline$A B 045$ & 517 & 363 & 265 & 73.0 & 98 & 27.0 & 70.2 \\
\hline AB031 & 410 & 316 & 240 & 76.0 & 76 & 24.0 & 77.1 \\
\hline ABO40 & 396 & 300 & 252 & 84.0 & 48 & 16.0 & 75.8 \\
\hline AB051 & 521 & 428 & 368 & 86.0 & 60 & 14.0 & 82.1 \\
\hline AB105 & 306 & 218 & 100 & 45.9 & 118 & 54.1 & 71.2 \\
\hline$A B 110$ & 314 & 246 & 114 & 46.3 & 132 & 53.7 & 78.3 \\
\hline AB135 & 401 & 283 & 135 & 47.7 & 148 & 52.3 & 70.6 \\
\hline AB140 & 421 & 316 & 155 & 49.0 & 151 & 51.0 & 75.1 \\
\hline AB144 & 423 & 287 & 155 & 54.0 & 132 & 46.0 & 67.8 \\
\hline$A B 167$ & 465 & 307 & 166 & 54.1 & 141 & 45.9 & 66.0 \\
\hline$A B 171$ & 467 & 354 & 192 & 54.3 & 162 & 45.7 & 75.8 \\
\hline $\mathrm{AB} 177$ & 403 & 273 & 150 & 54.9 & 123 & 45.1 & 67.7 \\
\hline$A B 179$ & 398 & 261 & 146 & 55.9 & 115 & 44.1 & 65.6 \\
\hline$A B 180$ & 388 & 252 & 141 & 56.0 & 111 & 44.0 & 64.9 \\
\hline AB183 & 423 & 311 & 175 & 56.3 & 136 & 43.7 & 73.5 \\
\hline AB192 & 465 & 341 & 198 & 58.1 & 143 & 41.9 & 73.3 \\
\hline $\mathrm{AB} 197$ & 411 & 287 & 167 & 58.2 & 120 & 41.8 & 69.8 \\
\hline AB199 & 312 & 192 & 112 & 58.3 & 80 & 41.7 & 61.5 \\
\hline
\end{tabular}


perlakuan pengalihan kelamin secara individual. Sanico (1975) yang memberikan perlakuan estrogen pada 0 . aureus dengan esiron memperoleh ratio seks yang diamati tidak berbeda nyata dengan kontrol, namum ternyata Liu (1977) yang meneruskan penelitian tersebut dapat menghasilkan anakan dengan populasi $100 \%$ jantan dari salah satu individu hasil pengalihan kelamin Sanico tersebut.

\section{KESIMPULAN DAN SARAN}

Perlakuan pengaihan kelamin melalui pemberian pakan yang diberi hormon $17 \mathrm{~b}$-estradiol dosis $100 \mathrm{mg} /$ kg pakan pada fase larva yang dilakukan pada tahun sebelumnya telah berhasil mendapatkan betina heterogamet fungsional sebanyak $9,75 \%$ dari total induk betina yang memijah.

\section{DAFTAR PUSTAKA}

Clemens, H.P. and T. Inslee. 1968. The production of unisexual broods by Tilapia mossambica sex reversed with methyltestosterone. Trans. Am. Fish. Soc., 97 (1): $19-21$.

Eckstein, B. and M. Spira. 1965. Effect of sex hormones on the gonadal differentiation in a cichlid. Tilapia aurea. Biol. Bull. (Woods Hole, Mass.), 129: 482-489.

Gordon, D.M., Maskur, and H. Sofi. 1995. Genetic Improvement of Red Tilapia Assessing the Potential for Proceedings YY Males. CUSO Cooperantion Project. Balai Budidaya Air Tawar, Direktorat Jenderal Perikanan, Departemen Pertanian Indonesia, 15 pp.

Guerrero, R.D. 1982. Control of tilapia reproduction. In: R.S.V. Pullin and R.H. Lowe McConnell (Eds.), The Biology and Culture of Tilapias. ICLARM, Manila, The Philippines, $434 \mathrm{pp}$.

Hanson, T.R., R.D. Smitherman, W.L. Shelton, and R.A. Dunham. 1983. Growth comparisons of monosex Tilapia produced by separation of sexes, hybridization and sex reversal. In L. Fishelson and Z. Yaron (Eds.), Proceedings of the International Symposium on Tilapia in Aquaculture, Tel Aviv University, Tel Aviv, 624 pp.

Hishida, T. and N. Kawamoto. 1970. Androgenic and male inducing effects of 11-ketotestosterone on a Teleost, the Medaka (Oryzias latipes). J. Exp. Zool, 170: $279-283$.

Hunter, G.A., E.M. Donaldson, J. Stoss, and I. Baker. 1982. Production of monosex female groups of chinook salmon (Oncorhynchus tshawytscha) by the fertilization of normal ova with sperm from sex reversed males. Aquaculture, 33: 355-364.

Jangkaru, Z., M. Sulhi, dan Sidi Asih. 1988. Pembesaran ikan nila jantan yang dipelihara secara tunggal kelamin dan campuran dalam kolam air tanah. Bulletin Penelitian Perikanan Darat. Balai Penelitian Perikanan Air Tawar, Bogor.
Jensen, G.L. and W.L. Shelton. 1979. Effect of estrogen on Tilapia aurea: Implication for production of monosex genetic male tilapia. Aquaculture, 16: 233-242.

Liu, C. Y. 1977. Aspects of reproduction and progeny testing in Sarotherodon aureus (Steindachner). In W.S. Hoar, D.J. Randal, and E.M. Donaldson (Eds.). 1983. Fish Physiology; Hormonal Sex Control and Its Aplication to Fish Culture. Vol IX-B. Accademic Press. New York, p. 223-303.

Majumdar, K.D. and B.J. McAndew. 1983. Sex ratios from inter-specific crosses within the tilapias. In L. Fishelson \& Z. Yaron (Eds.), Proceedings of the International Symposium on Tilapia in Aquaculture, Tel Aviv University, Tel Aviv, 624 pp.

Parsons, J.E. and G.H. Thorgaard. 1985. Production of androgenetic diploid rainbow trout. J. Hered, 76: $177-181$.

Pruginin, Y., S. Rothbard, G. Wohliarth, A. Halevy, R. Moav, and G. Hulata. 1975. All male broods of Tilapia nilotica $X$ Tilapia aurea hybrids. Aquaculture, 6: 11-21.

Sanico, A.F. 1975. Effects of 17 a ethynyl testosterone and estrone on sex ratio and growth of Tilapia aurea (Steindachner), In W.S. Hoar, D.J. Randal and E.M. Donaldson. 1983. Fish Physiology; Hormonal Sex Control and its Aplication to Fish Culture. Accademic Press. New York, IX-B: 223-303.

Scott, A.G. D.J. Penman, J.A. Beardmore, and D.O.F. Skibinski. 1989. The ' $Y Y$ ' Supermale in Oreochromis niloticus (L.) and its Potential in Aquaculture. Elsevier Science Publishers B.V., Amsterdam-Printed in Netherlands, 78: 237-251.

Shelton, W.L., K.D. Hopkins, and G.L. Jensen. 1978. Hormone-induced monosexing of tilapia for aquaculture. In R.O. Smitherman, W.L. Shelton, and J.H. Grover (Eds.), Culture of Exotic Fishes Symposium Proceedings. Fish Culture Section, Am. Fish. Soc., Auburn, AL, p. 10-33.

Tayamen, M.M. and W.L. Shelton. 1978. Inducement of sex reversal in Sarotherodon niloticus (Linnaeus). Aquaculture, 14 (4): $349-354$.

Wohlfarth, GW. and GI. Hulata. 1981. Applied genetics of tilapias. International Center for Living Aquatic Resources Management, Manila, The Philippines, ICLARM Studies and Reviews, (6): 26 pp.

Yamamoto, T. 1961. Progenies of induced sex-reversal females mated with induced sex-reversal males in the medaka, Oryzias latipes. J. Exp. Zool., 146: 163179.

Yamamoto, T. 1963. Induction of reversal in sex differentiation of $Y Y$ zygotes in the medaka, Oryzias latipes. Genetics, 50: $45-58$.

Yamamoto, T. 1964. The problem of viability of $Y Y$ zygotes in the medaka, Oryzias latipes. Genetics, 50:45--58.

Yamamoto, T. 1969. Sex Differentiation. In W.S. Hoar, D.J. Randal and E.M. Donaldson. 1983. Fish Physiology; Hormonal Sex Control and its Aplication to Fish Culture. Accademic Press. New York, IX-B. $223-303$. 
